\title{
Wh-Questions in English and Chinese: A Phase-Based Approach
}

\author{
Zheng Gao \\ School of Humanities, Tiangong University, Tianjin, China \\ Email: 807187823@qq.com
}

How to cite this paper: Gao, Z. (2021) Wh-Questions in English and Chinese: A Phase-Based Approach. Open Access Library Journal, 8: e7272.

https://doi.org/10.4236/oalib.1107272

Received: March 1, 2021

Accepted: March 23, 2021

Published: March 26, 2021

Copyright $\odot 2021$ by author(s) and Open Access Library Inc.

This work is licensed under the Creative Commons Attribution International License (CC BY 4.0).

http://creativecommons.org/licenses/by/4.0/

\section{(c) (i) Open Access}

\begin{abstract}
Wh-question has aroused considerable attention of linguists around the world. English is a wh-movement language, while Chinese is commonly recognized as a wh-in-situ language. By the advent of the Minimalist Program outlined by Chomsky, the syntactic derivation in a phase-based approach has reduced the computational operation. The syntactic structures are built in a bottom-up and one-phase-at-a-time way. Merge and Agree are the most basic syntactic operations. The paper presents how Phase Theory works and clarifies a computational model of generation of wh-questions. This model accounts for how the uninterpretable $[\mathrm{WH}]$ feature of wh-phrases is checked and deleted and when phrases are sent to Spell-Out. The paper tries to explore the similarity and difference of nominal wh-words between English and Chinese in matrix and embedded wh-questions, which will help provide further evidence of the power of universal grammar, and the usefulness of the approach to syntactic operation of other languages.
\end{abstract}

\section{Subject Areas}

Linguistics

\section{Keywords}

Wh-Questions, Phase Model, Minimalist Program, Merge, English and Chinese

\section{Introduction}

The syntactic analysis of wh-questions has aroused considerable attention of linguists in the last thirty years of generative syntax. Wh-question movement has been the focus of extensive syntactic analysis in Chomsky's (1981-1991) Government and Binding theory and the Minimalist Program (1995-2015) and other 
analyses of many syntacticians (Mushait, 2019) [1]. Linguists have made various discussions on wh-questions in different languages in order to present a unified treatment within universal grammar and parameters. Principles are considered universals on the basis of which it is suggested that all languages are similar, while on the other hand, parameters are regarded as those elements which mark sharp differences between different languages (Miller, 2016 [2]; Yeo, 2010 [3]; Givon, 2001 [4]). The paper tries to explore the generation of wh-questions in English and Chinese within the minimalist framework outlined by Chomsky (1998 [5], 1999 [6], 2001 [7]). The derivation is proceed based on Chomsky's (2001 [7], 2005 [8] [9], 2013 [10], 2015 [11]) Phase Theory. As Mandarin Chinese is commonly recognized as a wh-in-situ language, the wh-word like "shenme" as the wh-object following a $\mathrm{V}$ is not fronted as in English. A question that naturally arises is the syntactic difference of the wh-question derivation between English and Chinese. The study on Chinese's wh-questions in a phase-based approach is less. The paper tries to examine the minimalist computation about that in accord with the economy principle. The core objective of the paper is to demonstrate the derivation of wh-questions in English and Chinese and show the interaction between the Chinese and Chomsky's Phase approach, which will help provide further evidence of the power of universal grammar, and the usefulness of the approach to syntactic operation of other languages.

The paper is organized as follows. Section 2 will be a literature review on wh-questions in English and Chinese. Section 3 will review the grammatical computation within the MP, and introduce the theoretical basis and concepts of phase model. In Section 3, I will examine the wh-questions featured by wh-object and wh-subject in English proceeded by phase, showing that wh-phrases are copied in the Spec CP position. In Section 4, I offer syntactic analyses of wh-questions in Chinese based on Phase approach, showing how wh-questions can be derived in minimalist syntax. In Section 5, I compare the derivation of wh-questions in English and Chinese, showing the unified analysis and parameters under investigation. Section 6 will conclude the paper.

\section{Literature Review}

In the Minimalist Program, Chomsky (1995) [12] argues that the raising of a wh-operator to [Spec, CP] must be motivated by feature checking. Based on Chomsky's theory, various syntactic analyses and approaches have been offered in order to obtain a satisfactorily unified treatment of different categories of wh-questions and wh-questions in different languages across the world.

Cook \& Newson (2014) [13] argues that the movement of a Wh-expression states the movement of question component or interrogative phrase from an argument position towards the closest non-argument position which indicates complementizer phrase. Hadas (2017) [14] presents the distribution of intervention effects in English multiple wh-questions and figures out that intervention does not correlate with superiority. Instead, it makes reference to the LF repre- 
sentation of the question. Claudia Felser (2001) [15] puts forward The Single-Step Hypothesis that there are no intermediate steps in long wh-movement. Rather than creating a trail of phonetically null copies, long wh-raising takes place in a single step.

The movement parameters among different languages have aroused the attention of many linguistics. By the advent of Standard Theory and Extended Standard Theory of Chomsky in the 1970s, many scholars have questioned his argument on wh-movement, particularly in Chinese. Huang (1982a [16], 1982b [17]) is the first to point out the postulation of a covert wh-raising process at LF. Cheng (1991) [18] proposes Clausal Typing Hypothesis. The sentence type or the force is determined in the overt syntactic stage. Overt movement will not occur in languages with question particles, whose sentence type or the force is determined by question particles. The sentence type or force of languages without question particles is determined by word order. Aoun and Li (1993) [19] argue that in both English and Chinese, wh elements in situ need not raise to the Spec of Comp in the LF component, and it's the Qu-operator that is raised to the appropriate Spec of Comp position by S-Structure. Hooi (2005) [20] shows that an adverbial wh-phrase undergoes covert feature movement in MC, while a nominal wh-phrase undergoes covert phrasal movement. Wen, Guan \& Zhang (2015) [21] explores the derivation of wh-questions in English, Chinese and Korean based on CP-split Hypothesis proposed by Rizz (1977) [22]. Wh-phrases merge with ForceP with a strong Edge feature, which attracts wh-phrases to locate in its Spec position. TP has to experience an integral raising. Bayer (2015) [23] investigates Wh-in-situ systematically within the minimalist theories. He interprets different concepts related to Wh-in-situ, investigated parallels between Wh-extraction and Wh-in-situ, and difference between overt movement in Wh-in-situ, coping, pied-piping, Q-Binding and D-linking.

The previous researches have provided various accounts for the wh-questions. With respect to English, researches on long wh-movement and multiple wh questions are in disputes. The focus that drives study on Chinese wh-questions is the problem about wh-in-situ or wh-ex-situ. The research in-depth on syntactic derivation of Chinese wh-questions in a phase-based approach is few, which will be the emphasis in the paper.

\section{Theoretical Base}

\subsection{Grammatical System of MP}

The faculty of language is a component of human mind dedicated to language, linking with the performance system through sensorimotor system and conceptual-intentional system. Composed of computational system and lexicon, Language $\mathrm{L}$ is a device that generates a pair $<$ Phon, Sem $>$. An expression converges if it converges at both Phonetic and Semantic interfaces, otherwise, it will crash. UG makes available a set $\mathrm{F}$ of features (linguistic properties) and CHL (the computational procedure for human language) that access $\mathrm{F}$ to generate expres- 
sions (Chomsky, 1998) [5]. Language selects a subset [F] of $\{\mathrm{F}\}$, and proceeds operation by assembling elements of $\mathrm{F}$ into a lexicon Lex. Then the derivation will make a one-time selection lexical array LA from Lex. The derivation steps can be shown as follows.

1) a) Select $[F]$ from the universal feature set $F$.

b) Select Lex, assembing features from $[\mathrm{F}]$.

d) Select LA from Lex.

d) Map LA to Exp, with no recourse to [F] for narrow syntax.

(Chomsky, 1998) [5]

Narrow syntax, phonological component and semantic component are the components of grammar of L. The computational operation includes Merge, Agree and Move. In the process of derivation, DNS is transferred to the phonological and semantic systems for evaluation and interpretation. The spell-out applies cyclically through Merge, Agree or Move to access the Exp $<$ PHON, SEM $>$. Derivation by phase adopts locality and cyclicity of computational system and syntactic operation. A sentence is built step by step by phase, that is, constructed by successive application of two basic building operations: Merge and Move.

Merge, Agree and Move

Chomsky (1995 [12], 2000 [24], 2001 [7], 2005a [8], 2005b [9], 2006 [25], 2013 [10], 2015 [11]) introduces three syntactic operations: MERGE (or External Merge), MOVE (or Internal Merge), and AGREE. MERGE refers to the operation that combines two syntactic objects $\alpha$ and $\beta$ to form another syntactic object $\{\alpha, \beta\}$. That is, two objects ( $\alpha$ and $\beta$ ) are merged into an unordered set with a label determined by the head (either $\alpha$ or $\beta$ ).

2) Merge $(\alpha, \beta) \rightarrow\{\gamma\{\alpha, \beta\}\}$

The merged element will inherit the properties of one of the two objects $\alpha$ or $\beta$. The head determines the label, identifying the properties of the phase. MERGE is a binary and recursive operation. The syntactic operations are applied only to the root. $\alpha$ and $\beta$ can be merged at a time. $\alpha$ or $\beta$ cannot further merge with another object. The merged object can further merge with another object $\gamma$. The External Merge is to combine two objects from the LA. Foe example, buy and books are merged into a VP buy books. The VP can proceed for further merge. Internal Merge means that one of the elements merged comes from inside the other one. For example, the phrase what is merged with the phrase he will buy what, where what he will buy what will be constructed. Chomsky (2000) [24] proposes that the operation AGREE establishes a relation (agreement, Case-checking) between LI $\alpha$ and a feature F in some restricted search space (its domain). Agree involves feature-copying and feature-deletion. It is triggered by the need to eliminate uninterpretable features of both the head (the Probe) and the target (the Goal) in the probe's c-command domain. According to Chomsky, Merge or Agree (or their combination) preempts Move, which is a "last resort". MOVE is a costly operation, because the target need rise, and the feature is checked by the primitive operation AGREE only (Mushait, 2019) [1]. MOVE is 
the case of Internal Merge, where one of the elements merged comes from inside the other one. Move brings overt displacement of a sentence element in representation to satisfy the feature-checking.

\subsection{Derivation by Phase}

The term Phase is firstly proposed in work by Chomsky in 1998 where he states that a sentence is often decomposed into two phases: CP and vP. Chomsky (2001) [7] proposes "propositional" categories CP with force indicator and (transitive) vP with full argument structure. According to Chomsky, defective TPs and vPs are not phases for the reason that they do not have an external thematic argument. Therefore, $\mathrm{CP}$ and $\mathrm{v}^{\star} \mathrm{P}$ are phases. The heads of phases $\mathrm{v}^{\star} \mathrm{P}$ and $\mathrm{CP}$ carry an EPP feature, which allows overt movement that presupposes abstract agreement in order to eliminate uninterpretable features.

Chomsky (2015) [11] reveals that phases are the stages in the derivation, or nodes in the phrase marker, where the structure is transferred to the interface levels, and as a result it becomes no longer available for further syntactic operations. Chomsky (2000 [24], 2001 [7]) proposes the Phase Impenetrability Condition:

In phase $\alpha$ with head $\mathrm{H}$, the domain of $\mathrm{H}$ is not accessible to operations outside $\alpha$, only $\mathrm{H}$ and its edge are accessible to such operations.

PIC determines when phrases are sent to spell-out. It indicates that the head and its specifier are accessible to further syntactic operations, while the complement of the phase head becomes impenetrable to further syntactic operations. In short, phases are transferred simultaneously at PF interface and LF interface. The phase transferred becomes inaccessible to further syntactic operation. Values of uninterpretable features must be assigned within a phase to make sure the Exp converge.

\subsubsection{Feature Valuation}

Each lexical item in the brain is a set of features, among which some are valued/interpretable features and some are unvalued/uninterpretable features. Chomsky (2000) [24] proposes the distinction between interpretable features and uninterpretable features. Interpretable features refer to the features that play a role in semantic interpretation, and uninterpretable features vice verse. Features of some lexical items have not been determined before syntactic derivation, which should be assigned during syntactic derivation. Feature checking is the basis for the derivation by phase. Chomsky (1995) [12] divides the features of lexical items into category features; $\varphi$ features (person, gender and number); case features and strong feature F. For example, the person and number features of nouns and the tense features of verbs are interpretable features, while case feature of nouns and the person and number feature of verbs are uninterpretable features. Chomsky (2006) [25] claims that the semantic uninterpretable features of the internal components of a phase must be assigned within the phase before transferred, otherwise the phase computation crashes. 
The deletion of uninterpretable features relies upon the identification of agreement, the operation of Move and the establishment of head-specifier. Chomsky defines the unvalued features as the probe. The probe seeks for the goal in its c-command domain to establish agreement relationship, and the uninterpretable features will be valued and deleted. Chomsky (1999) [6] sees that both the probe and the goal must be active, for example, they must have uninterpretable features to be checked and AGREE deactivates them both by checking these features. Otherwise they will not be transferred to Spell-Out, and the derivation will crash.

Chomsky (2007 [26], 2008 [27]) states that T and V inherit uninterpretable features from phase head, so they are active and can be the probe that seeks its goal. The Head of core functional categories: complementizer $\mathrm{C}$, tense $\mathrm{T}$ and light verb v, all have an EPP feature. As EPP feature is uninterpretable, they have to merge a proper element which is in the specifier position of its projection structure to get the feature valued. The probe must have a complete set of $\varphi$-features and be active. The agreement relationship between probe and goal triggers the movement of goal. The EPP feature of $\mathrm{T}$ triggers the movement of noun or pronoun in the specifier place of $\mathrm{v}^{\star} \mathrm{P}$ to the specifier place of TP. The EPP feature of $\mathrm{C}$ triggers the movement of wh-expressions to the specifier place of CP.

The foundation of agreement relationship between probe and goal must satisfy the following conditions:

3) a) Probe $\alpha$ and goal $\beta$ must all be active in order for the agreement operation

b) Probe a must have complete $\varphi$ feature-set to delete the uninterpretable feature of its matching goal $\beta$ (Chomsky, 2001) [7].

In addition to the above two conditions, Chomsky (2008) [27] claims that probe must find its goal in minimal domain (constituent dominant domain) to satisfy minimal computation. The probe seeks the closest goal in its minimal domain. Available goals in the minimal domain should be equidistant from the probe.

\subsubsection{The Copy Theory of Movement}

Within the framework of generative grammar, when an element is moved, it leaves a trace in the original place. A key claim of the Minimalist Program is that all structure-building arises by means of a single mechanism, Merge (Chomsky 1995) [12]. According to MP, all the syntactic operations are simplified into Merge for economy and ideal design. The operation of internal merge generates several copies by coping instead of moving the relevant constituents off. After a constituent moves, what is left is a copy of the constituent, not a trace. The copy theory is proposed to satisfy Inclusiveness Condition:

Any structure formed by the computational system consists of constituents that are already present in the LI selected. In other words, no new constituents, e.g. indices, bar levels are added to the computation system in the process of derivation.

(Chomsky, 1995) [12]

The copy carries on features-set of its mother. Consequently, a chain is a se- 
ries of identical elements. At spell-out, only one copy reaches PF restricted by economy, but at LF all copies are available for interpretation.

Let's further exemplify the work of phase in the derivation of sentences with an example below:

4) A man was killed.

In Lexical Array LA $=\{\mathrm{T}$, John, was, elected $\}$, each item is a set of features, among which some are valued/interpretable and some are unvalued/uninterpretable. The personal feature and number feature of auxiliary "was" are uninterpretable, which are transcribed as [u-Person, u-Num]. With the NP a man, its case feature is uninterpretable, which is transcribed as [u-Case]. In the passive structure, $\mathrm{V}$ (was) killed has an internal argument with nominative case, but has no external argument. V has not a complete set of $\Phi$-features. The verb killed merges with a man to form VP, in which a man is assigned patient role. It has interpretable [3person, Single] features and [u-Case] feature. Then, $\mathrm{T}$ enters the computation to merge with VP, forming T'. T has a strong EPP feature. It has uninterpretable [u-Pers] and [u-Num] feature and interpretable [Case] feature. $\mathrm{T}$ plays the role of probe, searching for an NP with [3person, Single] features in the minimal domain. A man can be the available goal. Then, a copy of a man remerges to the Spec position of TP, where a man's case feature is valued as [Nominative] and EPP feature of $\mathrm{T}$ is deleted. At the PF interface, the lower copy of a man is not realized. That is, it is deleted as (5) shows.

5) [VPkilled a man]

[T" was [VPkilled a man]]

[TPA man[T' was killed]]]

\section{Derivation of Wh-Questions in English by Phase}

According to Chomsky, the head C has only an uninterpretable Q feature. The uninterpretable probe $[\mathrm{Q}]$ on the head $\mathrm{C}$ will be checked and deleted in the syntax by Q-agreement. Wh-phrases are equipped with [WH] feature. The EPP feature on the head $\mathrm{C}$ can account for the displacement of a wh-phrase, since uninterpretable features are checked without triggering overt movement within the MP framework. Chomsky assumes that the EPP-feature on the head C is similar to the EPP-feature of the head T, which requires the [Spec, $\mathrm{CP}]$ configuration to be filled. Therefore, it is assumed that wh-phrases are coped in [Spec-CP] in order to evaluate its $[\mathrm{WH}]$ feature.

\subsection{Matrix Wh-Questions}

The sentence in (6) is considered the example of analyzing the extraction of wh-questions from the object position. This can be shown in (6) below.

6) What did you buy?

[CP What C[EPP] did [v $\mathrm{P} \mathrm{v}^{\star}[\mathrm{EPP}]$ you [VP buy]]]

The derivation begins from selecting lexical items from the LA. We select contend words $\{$ you, did, buy, what $\}$ and functional categories $\{\mathrm{v}, \mathrm{C}\} . \mathrm{V}$ buy 
merges with its object complement DP what to from the VP; Because the phrase has an thematic external argument, VP merges with the subject DP you, thus forming the phase [ $\mathrm{v}^{*}$ you [VP buy what]. Since the $\mathrm{v}$ is a phase head, it has to probe for a local goal and hence it finds the object wh-phrase what with uninterpretable $[\mathrm{WH}]$ feature. The head $\mathrm{v}$ agrees with and assigns accusative case to the object wh-phrase what. Based on Chomsky's Phase analysis, it is assumed that the light transitive $\mathrm{v}$, acting as the head of the $\mathrm{v}^{\star} \mathrm{P}$ phase, has an EPP feature, which attracts the object wh-phrase what to be the second (outer) specifier of $\mathrm{v}^{\star} \mathrm{P}$. Consequently, what is copied to the left periphery of $\mathrm{v}^{\star} \mathrm{p}$, forming $\left[\mathrm{v}^{\star} \mathrm{P}\right.$ what $\mathrm{v}^{\star}$ you [VPbuy what]. The head $\mathrm{v}$ of $\mathrm{v}^{\star} \mathrm{p}$ has not got $\Phi$-features. The phase can not be transferred to Spell-Out. Then $v^{\star} \mathrm{p}$ merges with the auxiliary did located in the head $\mathrm{C}$ which has an Edge feature; the latter re-merges the copy of the wh-phrase in the edge of $\mathrm{v}^{\star} \mathrm{P}$ and locates in [Spec, CP]. Thus the uninterpretable [Q] feature of the matrix $\mathrm{C}$ and $[\mathrm{u}-\mathrm{WH}]$ of wh-phrase what will be checked and deleted. Furthermore, the derivation ends and is transferred to PF and LF.

7) Who bought the book?

[CP Who C[EPP] [v*P $\mathrm{v}^{\star}[\mathrm{EPP}]$ [VP bought the book]]]

The derivation begins from selecting lexical items from the LA. We select contend words $\{$ who, bought, the book $\}$ and functional categories $\{\mathrm{v}, \mathrm{C}\}$. The $\mathrm{V}$ bought merges with the object NP the book, thus forming the VP projection. The phrase VP has an external thematic argument who, which is located in its specifier position. VP merges with the subject wh-phrase who in the specifier position to form a $\mathrm{v}^{\star}\left[\mathrm{v}^{\star}\right.$ who [VP bought the book]. The head $\mathrm{v}$ of the phase $\mathrm{v}^{\star} \mathrm{P}$ searches for a local goal. The DP complement is the matching goal under agreement and then is assigned accusative case. The light transitive $\mathrm{v}$, acting as the head of the $\mathrm{v}^{\star} \mathrm{P}$ phase, has an EPP feature, which attracts the object wh-phrase what to be the second (outer) specifier of $\mathrm{v}^{\star} \mathrm{P}$. Consequently, who is copied to the left periphery of $\mathrm{v}^{\star} \mathrm{p}$, forming $\left[\mathrm{v}^{\star} \mathrm{P}\right.$ who $\mathrm{v}^{\star}$ who [VP bought the book]. According to Phase theory, since the VP is in the $\mathrm{v}^{\star} \mathrm{P}$ 's domain, the former must be transferred to the PF and LF interface levels for the necessary interpretation in order for the derivation to converge. The lower copy left behind receives a null Spellout in the phonological component. This ensures that the VP projection cannot be accessed to any further morpho-syntactic operations and that it cannot probe even from outside the $\mathrm{v}^{\star} \mathrm{P}$ phase. Furthermore, the $\mathrm{v}^{\star} \mathrm{P}$ phase merges with the null phase head $\mathrm{C}$ in order to from the C-bar projection. In English the phase head $\mathrm{C}$ has an EPP feature, it projects into the CP. As the head $\mathrm{C}$ is a probe, it has to search for a goal in its domain. The head $\mathrm{C}$ has an uninterpretable $[\mathrm{Q}]$ feature to be checked. The head $\mathrm{C}$ locates the goal the subject wh-word who being the only available candidate, with which it agrees and assigns invisible nominative case. The presence of the EPP feature of $\mathrm{C}$ attracts the copy who in [Spec, CP]. The uninterpretable feature [wh] of wh-word who is checked by the agreement between Spec-Head and then is deleted. The subject wh-phrase who and the head Phase $\mathrm{C}$ have to undergo a mandatory transfer to 
the PF and LF levels, thus ensuring that the wh-structure is interpreted as interrogative in the syntax. Finally, the grammatical wh-question in (7) above has been derived successfully.

\subsection{Embedded Wh-Questions}

8) I wonder what Bob is watching.

[CP1[TP1[I wonder [CP2 What [C[EPP][TP2[Bob is watching ]]]]]]]

The derivation begins from selecting lexical items from the LA. We select contend words $\{\mathrm{I}$, wonder, Bob, is, watching, what $\}$ and functional categories $\{\mathrm{V}$, $\mathrm{T}, \mathrm{C}$. The $\mathrm{V}$ watching merges with the object NP what, thus forming the VP projection. The phase VP merges with the auxiliary is, forming a T'. Bob is an external thematic argument, located in [Spec, TP]. TP2 then merges the null phase head C in order to from the C-bar projection. In English the phase head C has an Edge feature (EF), it projects into the $\mathrm{CP}$. As the head $\mathrm{C}$ is a probe, it has to search for a goal in its domain. The head $\mathrm{C}$ has an uninterpretable [Q] feature to be checked. The head $\mathrm{C}$ locates the goal the object wh-word what being the only available candidate. The presence of the EPP feature of $\mathrm{C}$ attracts the copy who to be in [Spec, CP2]. The uninterpretable feature [WH] of wh-word what is checked via the agreement between Spec-Head and then is deleted. CP2 has to undergo a compulsory transfer to the PF and LF levels. The next step is to merge with CP1. As TP is in CP's domain, I wonder will be transferred to Spellout. The higher copy of wh-word what locates at CP2 instead of CP1 as the latter is characterized by being $[-\mathrm{WH}]$, in turn, declarative in force. Finally, the grammatical wh-question in (8) above has been derived successfully.

\section{Derivation of Wh-Questions in Chinese by Phase}

Different from English, the head C carries weak [+WH] specifier feature in Chinese, which fails to attract the movement of wh-word in its specifier position. According to $\mathrm{Ma}$ (2016), he proposes the Interrogative Feature Attraction Hypothesis that the wh-feature of a wh-XP (a word or a wh-phrase) must be attracted to spec CP in wh-questions for wh-feature checking requirement. In Null Spec type of languages such as Chinese, the head null complementizer carries weak $[+\mathrm{WH}]$ specifier feature, attracted by the sentential affix "ne" or tone $\mathrm{Q}$, which only attracts the wh-feature of the wh-word or the wh-phrase to move to spec $\mathrm{CP}$ in the matrix clause so that the $[\mathrm{WH}]$ specifier feature of $\mathrm{C}$ is checked and the sentence is interpreted and an interrogative sentence (Ma, 2016).

\subsection{Matrix Wh-Questions}

9) Ni maile shenme?

You bought what?

[CP C[TP ni[T[ $\mathrm{v}^{\star} \mathrm{P}\left[\mathrm{v}^{\star}[\mathrm{VP}\right.$ maile shenme $\left.\left.\left.\left.]\right]\right]\right]\right]$

The derivation begins from selecting lexical items from the LA. We select contend words $\{$ ni, maile, shenme $\}$ and functional categories $\{\mathrm{v}, \mathrm{C}\}$. The V maile 
merges with the object NP shenme, thus forming the VP projection. The VP has an external thematic argument $n i$, which is located in its specifier position of $\mathrm{v}^{\star} \mathrm{P}$. The phase $\left[\mathrm{v}^{\star} \mathrm{P} \mathrm{ni}\left[\mathrm{v}^{\star}[\mathrm{VP}\right.\right.$ maile shenme $\left.]\right]$ is derived, where the complement shenme has a $[\mathrm{WH}]$ feature. In the phase $\mathrm{v}^{\star} \mathrm{P}$, the [WH] feature of shenme can not be checked, and the agreement feature of the head $v$ in $v^{\star} p$ has not been valued. The phase $v^{\star} \mathrm{P}$ proceeds for further syntactic operation. $\mathrm{V}^{\star} \mathrm{P}$ merges with null $\mathrm{T}$ to form $\mathrm{TP}$ projection. The head $\mathrm{T}$ is the probe which probes in order to locate the goal in its governing domain. However, there are two available goals: the first one is the object wh-phrase shenme, and the second is the subject DP ni. $B$ ut the $[\mathrm{WH}]$ feature of shenme cannot be checked in [Spec, TP]. Therefore, $n i$ is coped in the Spec TP position, forming [TP ni $\mathrm{T}\left[\mathrm{v}^{\star} \mathrm{P}\right.$ ni[ $\mathrm{v}^{\star}[\mathrm{VP}$ maile shenme]]]]. As a result, the head $\mathrm{T}$ agrees with and assigns nominative Case to the subject DP ni. As the [WH] feature of shenme fails to be checked, and TP is not a phase, thus no spell out occurs. The next step is to from the phase CP. TP projection merges with the null interrogative phase head C; the latter merges with a null Spec. The wh-feature of the DP shenme is attracted by the weak specifier feature of the head $\mathrm{C}$ and moved to spec $\mathrm{CP}$ to check the specifier feature of the head. The $[\mathrm{WH}]$ feature of the wh-word shenme agrees with the weak specifier feature of the head $\mathrm{C}$. Thus the uninterpretable [Q] feature of the matrix $\mathrm{C}$ and $[\mathrm{u}-\mathrm{WH}]$ of wh-phrase shenme will be checked and deleted. Furthermore, the derivation ends and is transferred to PF and LF.

10) Shui maile zheben shu?

Who bought the book?

[CP C[TP shui[T[ $\mathrm{v}^{\star} \mathrm{P}\left[\mathrm{v}^{\star}[\mathrm{VP}\right.$ maile zheben shu]]]]]]

The derivation begins from selecting lexical items from the LA. We select contend words \{shui, maile, zheben, shu $\}$ and functional categories $\{\mathrm{v}, \mathrm{T}, \mathrm{C}\}$. The V maile merges with the object NP zheben shu, thus forming the VP projection. The VP merges with a light affixal $\mathrm{v}$ in order to form $\mathrm{v}^{\star} \mathrm{P}$. The phase has an external thematic argument shui. $V^{\star}$ merges with the subject wh-phrase shui in the specifier position of $\mathrm{v}^{\star} \mathrm{P}$ to form a phase $\left[\mathrm{v}^{\star} \mathrm{P}\right.$ shui $\left[\mathrm{v}^{\star}[\mathrm{VP}\right.$ maile zheben shu]]], where the specifier of $\mathrm{v}^{\star} \mathrm{P}$ shui has a [WH] feature. The head $\mathrm{v}$ of the phase $\mathrm{vP}$ searches for a local goal. The DP complement zheben shu is the matching goal under agreement and then is assigned accusative case. In the phase $\left[\mathrm{v}^{\star} \mathrm{P}\right.$ shui[ $\left[\mathrm{v}^{\star}[\mathrm{VP}\right.$ maile zheben shu]]], the [WH] feature of shui in the Spec position can not be valued. The phase $\mathrm{v}^{\star} \mathrm{P}$ proceeds for further syntactic operation. $\mathrm{V}^{\star} \mathrm{P}$ merges with a null $\mathrm{T}$ to form TP projection. Since $\mathrm{T}$ has an EPP feature, shui is coped in the spec TP position, forming [TP shui[ $\left[\mathrm{v}^{\star} \mathrm{P}\right.$ shui[ $\left[\mathrm{v}^{\star}[\mathrm{VP}\right.$ maile zheben shu]]]]]. As a result, the head $\mathrm{T}$ agrees with and assigns nominative Case to the subject DP shui. As the [WH] feature of shui in the Spec position fails to be checked, and TP is not a phase, thus no spell out occurs. The next step is to from the phase CP. TP projection merges with the null interrogative phase head $\mathrm{C}$ which has an Edge feature; the latter merges with a null Spec of $\mathrm{CP}$, form the phase[CP C[TP shui[ $\left[\mathrm{v}^{\star} \mathrm{P}\right.$ shui[ $\mathrm{v}^{\star}[\mathrm{VP}$ maile zheben shu]]]]]. 
The wh-feature of the DP shui is attracted by the weak specifier feature of the head $\mathrm{C}$ and moved to spec $\mathrm{CP}$ to check the specifier feature of the head. The $[\mathrm{WH}]$ feature of the wh-word shui agrees with the weak specifier feature of the head C. Thus the uninterpretable [Q] feature of the matrix $\mathrm{C}$ and $[\mathrm{u}-\mathrm{WH}]$ of wh-phrase shui will be checked and deleted. Furthermore, the derivation ends and is transferred to PF and LF.

\subsection{Topic Wh-Questions}

11) Naben shu, zhangsan xihuan?

Which book, Zhangsan like?

[CP naben shu[TPZhangsan [T[ $\mathrm{v}^{\star} \mathrm{P}\left[\mathrm{v}^{\star}[\mathrm{VP}\right.$ xihuan] ] ] ]

As Chinese is a topic prominent language (Li \& Tompson, 1976, 1981), an example in given in the paper to examine such kind of syntactic operation of wh-questions. It may be hypothesized that in Chinese $\mathrm{C}$ possesses peripheral feature of topic (Ma, 2016) [28]. The derivation begins from selecting lexical items from the LA. We select contend words \{naben, shu, zhangsan, xihuan\} and functional categories $\{\mathrm{v}, \mathrm{T}, \mathrm{C}\}$. The $\mathrm{V}$ xihuan merges with the object NP naben $s h u$, thus forming the VP projection. The phrase VP has an external thematic argument Zhangsan, which is located in its specifier position. The light $\mathrm{v}$ has an EPP feature. The head $v$ of the phase $\mathrm{v}^{\star} \mathrm{P}$ searches for a local goal. The DP complement naben shu is the matching goal under agreement and then is assigned accusative case. The object wh-phrase naben shu to be the second (outer) specifier of $\mathrm{v}^{\star} \mathrm{P}$, forming the phase $\left[\mathrm{v}^{\star} \mathrm{P}\right.$ naben shu [ $\mathrm{v}^{\star}$ Zhangsan[VP xihuan naben shu]]]. The head $v$ of $v^{\star} p$ has not acquired agreement feature. The phase can not be transferred to the Spellout. Then $v^{*} p$ merges with $\mathrm{T}$ to form TP projection, where the head $\mathrm{T}$ is the probe which probes in order to locate the goal in its governing domain. The subject Zhangsan is the matching goal. Because the object wh-phrase naben shu has been assigned accusative case by the verb xihuan. The agreement feature of head T triggers the movement of Zhangsan, which moves to TP and forms [TPZhangsan [T $\left[\mathrm{v}^{\star} \mathrm{P}\right.$ naben shu [ $\mathrm{v}^{\star}$ Zhangsan[VP xihuan naben shu] ]]]]. As a result, the head $\mathrm{T}$ agrees with and assigns nominative Case to the subject DP Zhangsan. The next step is to from the phase CP. TP projection merges with the head $\mathrm{C}$ which possesses peripheral feature of topic; the latter attracts the wh-phrase naben shu to move to $\mathrm{C}$, forming the phase [CP naben shu[TPZhangsan [T[ $\mathrm{v}^{\star} \mathrm{P}$ naben shu [ $\mathrm{v}^{\star}$ Zhangsan[VP xihuan naben shu]]]]]]. The lower copies are mot realized. Therefore, if the wh-phrase is the topic in Chinese sentences, the wh-phrase is moved to the head C in a bottom-up way. The movement of wh-phrases in base-generated topics agrees with Pan's (2014) [29] four types of wh-ex-situ.

\section{Conclusions}

I have demonstrated how this computational model successfully derives the syntactic representation under the framework of MP. Crucially, the phase 
model helps to clarify our understanding of how sentences are generated from the perspective of Phase Theory. The paper has discussed the derivation of wh-questions in English and Chinese in a phase-based approach. We hold the same opinion, as most of scholars, that Chinese is a wh-in-situ language. The head $\mathrm{C}$ has strong $[\mathrm{WH}]$ feature in English and weak [WH] feature in Chinese. It has been observed that for the extraction of wh-words from the object position in English, the wh-words are copied in Spec CP position for feature valuation and feature checking, while the wh-phrases as the DP object remain in-situ in Chinese based on WH Feature Attraction Hypothesis. Thus the movement of wh-phrases is mandatory in English and is not in Chinese. It has been shown that in the case of subject wh-raising, the VP must be transferred to the PF and LF interface levels for the necessary interpretation, which is different from the object wh-rasing for the uninterpretable feature of the wh-word in the object position. The wh-word in Chinese sentences locates in Spec TP for meeting T's EPP feature. The question feature agrees with the weak specifier feature of the head $\mathrm{C}$, which attracts the $[\mathrm{WH}]$ feature of the wh-word. In embedded wh-questions, wh-phrases are located in [Spec, CP2] instead of CP1, and the movement of $\mathrm{T}$ to $\mathrm{C}$ is not involved for its declarative force. The topic in Chinese is prominent. Linguists hold different opinions toward its syntactic derivation. The paper holds that Chinese $\mathrm{C}$ possesses peripheral feature of topic. The topic wh-phrases locate at the $\mathrm{C}$ position, and the $[\mathrm{WH}]$ feature can be checked and deleted.

Findings from this study make a contribution to research on wh-questions. Particularly, the MP provides a phase model to demonstrate the syntactic derivation of wh-questions in Chinese, a wh-in-situ language. Issues concerning the generation have been addressed in the paper. On one hand, the paper has exemplified the theoretical feasibility of the phase model that is not yet mature in a comparative way. On the other hand, the paper tries to raise concerns of linguistic learners with respect to different wh-question structures. I leave for future work in depth discussion of the many details of this model, as well as its application to a variety of other examples in other languages. It remains to be proved that the paper does not take the wh-words as indefinities into consideration. Besides, it ignores adverbial wh-phrases and wh-questions with question particles like ne and ma in Chinese. In recent years, Chomsky has been exploring language evolution from the biological perspective. He (2017) [30] proposes that Merge is a good candidate for the minimalist computational operation. The optimal computational operation, Merge, does not change the merged elements, and Merge imposes no order on the merged elements. Derivation of wh-questions by Merge should be an important topic for further research.

\section{Conflicts of Interest}

The author declares no conflicts of interest regarding the publication of this paper. 


\section{References}

[1] Mushait, S.A. (2019) The Derivation of Wh-Questions in Najrani Arabic. International Journal of Linguistics, 11, 181. https://doi.org/10.5296/ijl.v11i5.15238

[2] Miller, J. (2016) Introduction to English Syntax. Edinburgh University Press, Edinburgh.

[3] Yeo, W.N. (2010) Unifying Optional Wh-Movement. Doctoral Dissertation, University of York, York.

[4] Givón, T. (2001) Syntax: An Introduction (Vol. 1). John Benjamins Publishing, Amsterdam. https://doi.org/10.1075/z.syn1

[5] Chomsky, N. (1998, 2000) Minimalist Inquiries: The Framework, Preliminary Version in MIT Working Papers in Linguistics No. 15. In: Martin, R., Michaels, D. and Uriagereka, J., Eds., Step by Step: Essays on Minimalist Syntax in Honor of Howard Lasnik, MIT Press, Cambridge, 89-155.

[6] Chomsky, N. (1999) Derivation by Phase. MIT, Cambridge.

[7] Chomsky, N. (2001) Beyond Explanatory Adequacy. MIT, Cambridge.

[8] Chomsky, N. (2005) On Phases. MIT, Cambridge.

[9] Chomsky, N. (2005) Three Factors in Language Design. Linguistic Inquiry, 36, 1-22. https://doi.org/10.1162/0024389052993655

[10] Chomsky, N. (2013) Problems of Projections. Lingua, 130, 33-49. https://doi.org/10.1016/j.lingua.2012.12.003

[11] Chomsky, N. (2015) Problems of Projection: Extensions. In: Di Domenico, E., Hamann, C. and Matteini, S., Eds., Structures, Strategies and Beyond: Studies in Honour of Adriana Belletti, Linguistik Aktuell/ Linguistics Today, 223, John Benjamins, Amsterdam, 1-16. https://doi.org/10.1075/la.223.01cho

[12] Chomsky, N. (1995) The Minimalist Program. The MIT Press, Cambridge.

[13] Cook, V. and Newson, M. (2014) Chomsky's Universal Grammar. John Wiley \& Sons, Hoboken.

[14] Kotek, H. (2017) Dissociating Intervention Effects from Superiority in English Wh-Questions. The Linguistic Review, 34, 397-417. https://doi.org/10.1515/tlr-2017-0005

[15] Felser, C. (2001) Wh-Copying, Phase, and Successive Cyclicity. Essex Reserch Report in Linguistics, 37, 43-78.

[16] Huang, C.-T.J. (1982) Logical Relations in Chinese and the Theory of Grammar. PhD Dissertation, MIT, Cambridge.

[17] Huang, C.-T.J. (1982) Move Wh in a Language without Wh-Movement. Linguistic Review, 1, 369-416. https://doi.org/10.1515/tlir.1982.1.4.369

[18] Cheng, L.L.-S. (1991) On the Typology of WH-Questions. PhD Dissertation, MIT, Cambridge.

[19] Aoun, J. and Li, Y.-H.A. (1993) Wh-Elements in Situ: Syntax or LF? Linguistic Inquiry, 24, 199-238.

[20] Soh, H.L. (2005) Wh-in-Situ in Mandarin Chinese. Linguistic Inquiry, 36, 143-155. https://doi.org/10.1162/ling.2005.36.1.143

[21] Wen, L.T., Guan, S.S. and Zhang, Z.N. (2015) Phase Derivation of WH-Interrogatives among English, Chinese and Korean. Dongjiang Journal, 32, 16-21+111.

[22] Rizzi, I. (1977) The Fine Structure of the Left Periphery. In: Haegeman, L., Ed., Elements of Grammar, Kluwer Academic Publishers, Amsterdam, 281-337. 
[23] Bayer, J. (2015) Doubly-Filled Comp, Wh Head-Movement, and Derivational Economy. In: van Oostendorp, M. and van Riemsdijk, H., Eds., Representing Structure in Phonology and Syntax, De Gruyter, Berlin, 7-39. https://doi.org/10.1515/9781501502224-002

[24] Chomsky, N. (2000) Minimalist Inquiries: The Framework. In: Martin, R., Michaels, D. and Uriagereka, J., Eds., Step by Step: Essays on Minimalist Syntax in Honor of Howard Lasnik, MIT Press, Cambridge, 89-155.

[25] Chomsky, N. (2006) Approaching UG from Below. Unpublished Paper, MIT, Cambridge.

[26] Chomsky, N. (2007) Approaching UG from Below. Interfaces+Recursion = Language? In: Sauerland, U. and Gärtner, H.-M., Eds., Chomsky's Minimalism and the View from Syntax-Semantics, Mouton de Gruyter, Berlin, 1-29.

https://doi.org/10.1515/9783110207552-001

[27] Chomsky, N. (2008) On Phases. In: Freidin, R., Otero, C.P. and Luisa Zubizarreta, M., Eds., Foundational Issues in Linguistic Theory. Essays in Honor of Jean-Roger Vergnaud, MIT Press, Cambridge, 133-166.

https://doi.org/10.7551/mitpress/9780262062787.003.0007

[28] Ma, D.S. (2016) An Outline of English and Chinese Syntax. World Book Publishing Company, Guangzhou.

[29] Pan, J.-N. (2014) Wh-ex-Situ in Mandarin Chinese: Mapping between Information Structure and Split CP. Linguistic Analysis, 39, 371-414.

[30] Chomsky, N. (2017) Language Architecture and Its Import for Evolution. Neuroscience \& Biobehavioral Reviews, 81, 295-300.

https://doi.org/10.1016/j.neubiorev.2017.01.053 